\title{
Perceptions and barriers regarding telemedicine services among Bangladeshi young adults in the COVID-19 pandemic: A qualitative exploration
}

\author{
Quazi Maksudur Rahman ${ }^{1}$, Md. Estiar Rahman ${ }^{1, *}$, Rashenda Aziz ${ }^{2}$, Mamun Ur Rashid Pranta ${ }^{1}$, \\ Abdullah Al Zubayer ${ }^{3}$, Md. Bulbul Islam ${ }^{4}$, Md. Rifat Al Mazid Bhuiyan ${ }^{5}$, Kamrul Ahsan Khan $^{6}$, \\ Ashraf Uddin Chowdhury ${ }^{6}$, Liakat Hosain ${ }^{6}$
}

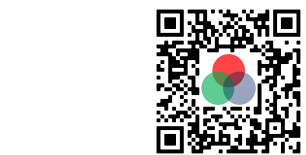

Use your smartphone to scan this QR code and download this article

${ }^{1}$ Department of Public Health \& Informatics, Jahangirnagar University, Savar, Dhaka, Bangladesh

${ }^{2}$ Department of Public Health, North South University, Dhaka, Bangladesh

${ }^{3}$ Department of Sociology, University of Barishal, Barishal, Bangladesh

${ }^{4}$ Centre for Entrepreneurship Development (CED), BRAC University (BRACU), Mohakhali, Dhaka, Bangladesh

${ }^{5}$ Dhaka Community Medical College,Mogbazar, Dhaka, Bangladesh

${ }^{6}$ Sheikh Sayera khatun Medical College, Gopalganj, Bangladesh

Correspondence

Md. Estiar Rahman, Department of Public Health \& Informatics, Jahangirnagar University, Savar, Dhaka, Bangladesh

Email: estiar@phiju.edu.bd

History

- Received: 2020-08-19

- Accepted: 2020-11-16

- Published: 2020-12-04

DOI : 10.15419/ajhs.v6i2.477

\section{Check for updates}

Copyright

(C) Biomedpress. This is an openaccess article distributed under the terms of the Creative Commons Attribution 4.0 International license.

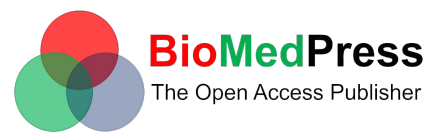

\begin{abstract}
The present study aimed to explore perceptions and barriers regarding telemedicine services among Bangladeshi young adults. This qualitative study was performed through telephonic interviews where 20 young adults (cases) were taken for in-depth interviews, using a purposive sampling technique from July 1 to July 20, 2020. The verbatim transcriptions was used, and the thematic analysis was performed through manual coding. The findings of this study revealed that the majority of participants perceived telemedicine as it is a system through which we are able to get healthcare services by using the internet, mobile application, or just a phone call from health care providers. Participants had positive attitudes toward telemedicine. Low trustworthiness, difficulties in getting access to emergency diagnostic services, significant anxieties on the use of telemedicine complexity and observability, shortage of network and power supply, as well as financial complexities were acknowledged as significant barriers in terms of receiving telemedicine services during the COVID-19 outbreak. Concerned authorities, including governmental and private organizations, should take effective measures to make telemedicine services available, reliable, and affordable for all across the country.

Key words: Telemedicine, Perception, Barriers, Young-adults, COVID-19 pandemic, Bangladesh
\end{abstract}

\section{INTRODUCTION}

Telemedicine refers to the delivery of health care services by healthcare professionals using Information and Communication Technology (ICT) for the exchange of vital information for the diagnosis, treatment, and prevention of disease and injuries, research and evaluation, and for the continuing education of health care providers, all in the interest of advancing the health of individuals and their communities, where distance is a critical factor ${ }^{1}$. A previous study in Bangladesh reported that people perceived telemedicine as a service for prescription of medicines, assessment of disease, and referral of diagnostic tests by using technologies such as the internet, computer, or webcam ${ }^{2}$. ICT systems have been using globally to deliver distant healthcare services via telemedicine ${ }^{3}$. Telemedicine allows healthcare professionals to evaluate, diagnose, and treat patients in remote locations using telecommunications technology $^{4}$. The COVID-19 pandemic poses a considerable obstacle to receive healthcare for non-COVID-19 patients. Telemedicine technology is being used in order to reduce the risk of COVID-19 spread both in the
United Kingdom and the United States of America ${ }^{5}$. In the digital health items introduced by the Australian government for the COVID 19 pandemic, over 4.3 million medical and health services have already been provided to more than three million patients ${ }^{6}$. A survey conducted by G\&S Business Communications found that $82 \%$ of Americans still don't think telehealth is available to them. Two out of five said the COVID-19 pandemic made them more likely to use telehealth ${ }^{7}$. In response to the novel coronavirus, the demand for telemedicine has been growing swiftly. A recent survey has been shown that $23 \%$ of adults in the USA have been used telehealth services considering the COVID-19 pandemic $^{8}$. A survey has been conducted through a software provider named MDLIVE regarding telemedicine and found that $82 \%$ of young adults aged 18 to 34 found using a mobile phone is the best option to consult with the doctors ${ }^{9}$. Moreover, the provision of telemedicine is far less progressed in lower-middle and low-income countries ${ }^{1}$. Many difficulties and challenges that arise from the implementation of telemedicine occur in both urban and rural areas ${ }^{10}$. Generally, people in rural areas tend to have

Cite this article : Rahman Q M, Rahman M E, Aziz R, Pranta M U R, Zubayer A A, Islam M B, Bhuiyan M R $A M$, Khan K A, Chowdhury A U, Hosain L. Perceptions and barriers regarding telemedicine services among Bangladeshi young adults in the COVID-19 pandemic: A qualitative exploration. Asian J. Health Sci.; 6(2):18. 
more restricted access to healthcare resources compared to those living in urban areas ${ }^{11}$. Lack of access to affordable broadband at adequate connection speeds is another roadblock to providing telemedicine in rural areas ${ }^{12}$. Treatment via telemedicine does not occur face-to-face; this does not change the fact that certain interactions establish a physician-patient relationship ${ }^{13}$. There are also linguistic barriers present regarding telemedicine services. In some developing countries such as India and Iran, there is a great diversity of languages, cultural aspects, and dialects. The diversity of languages and dialects makes it difficult to build acceptable verbal communication between physician and patient ${ }^{14}$.

Bangladesh is one of the most densely populated lower-middle-income countries where around $85 \%$ of the total population lives in rural areas ${ }^{15}$. On March 8, 2020, when the first COVID-19 case has been found in Bangladesh, hospital visit has been restricted, the majority of the doctors stopped practicing in person for self-protection. As a result, public and private organizations introduce telemedicine services. The traditional health care system is more in use than the electronic health care system in Bangladesh. According to the Directorate General of Health Services (DGHS), at present 94 facilities in Bangladesh, including 9 government specialized and medical college hospitals, 11 district hospitals, and more than 50 Upazila level hospitals, have the equipment to provide healthcare by videoconference ${ }^{16}$. In Bangladesh, the spread of the deadly COVID-19 caused people to maintain social distancing, movement restrictions, stay at home. Moreover, telemedicine still poses certain limitations in terms of treating patients during the COVID-19 pandemic ${ }^{17}$. As a developing country, Bangladesh is facing various obstacles to the promotion and implementation of e-Health, including telemedicine. Some major threats and challenges have been identified in our country, which includes: highcost, the lower liability of internet access, lack of appropriate information and technology policy, lack of coordination as well as lack of awareness of government and citizens ${ }^{18}$. Lack of patient satisfaction is one of the major barriers as well as another significant barrier is the lack of patient's trustworthiness towards telemedicine adaptation ${ }^{19}$. Moreover, the insufficient power supply might be the primary challenges and barriers to telemedicine implementation in Bangladesh ${ }^{20}$.

Based on the previous studies, limited information has been found on perceptions and barriers regarding telemedicine services among young adults, how they perceived telemedicine services qualitatively. Globally there are about 1.8 billion young out of 7.3 billion populations where majority of them are from developing countries like Bangladesh and nearly 30 percent of total population in Bangladesh is in young stage. Furthermore, developing countries emphasized more on youth investment, especially on their health services for social development. On the contrary, more than eighty percent young adults preferred phones for taking virtual treatment services above mentioned $^{9,21}$. Therefore, the present study aimed to explore perceptions and barriers regarding telemedicine services among Bangladeshi young adults in COVID-19 pandemic through a qualitative approach.

\section{METHODS - MATERIALS}

In this qualitative study, the purposive sampling technique was performed for collecting data from 20 young adults (cases) living in the community (urban, semi-urban, and rural) from 1 July to 20 July 2020. In-depth interviews were performed over the phone by considering the convenient state of the participants, and the data collection was continued until it reached its maturation process. The inclusion criteria included: participants who willingly agreed to take part in an online interview. The exclusion criteria included: the participants who were unable to participate in an online interview. The IDI questionnaires were as followed: (1) perception regarding telemedicine services, (2) perception in respect of barriers of telemedicine, and (3) recommendations to overcome the existing barriers from participants.

Each interview took approximately 15 - 18 minutes, and the audio recording was also used. All participant's consent was taken during the data collection process and assured that their personal information will be kept strictly confidential and won't be used for any other purposes. The verbatim transcriptions were performed, and the transcripts were cross-checked with the audio taping for finding out which important portions were missed via technical errors. Thematic analysis was performed for summarizing, extracting, and formulating texts through a manual coding system.

In this study, credibility was ensured by the pledge of the researchers in the period of their data collection in which interviewees were able to understand the research objectives. Credibility was also performed in the data analysis phase by the researchers. 
Table 1: Socio-demographic information of the study participants

\begin{tabular}{llll}
\hline Variable & Level & Frequency & Percentage \\
\hline Age (in years) & $18-28$ & 10 & 50.0 \\
Gender & $29-38$ & 10 & 50.0 \\
Male & Female & 10 & 50.0 \\
Occupation & Student & 10 & 50.0 \\
& Housewife & 4 & 20.0 \\
& Govt. employee & 2 & 10.0 \\
& Private employee & 3 & 10.0 \\
& Teacher & 3 & 15.0 \\
& Doctor & 1 & 15.0 \\
Residence & Business & 5 & 5.0 \\
& Rural & 8 & 25 \\
& Semi-urban & 5 & 40.0 \\
& Urban & 7 & 25.0 \\
\hline
\end{tabular}

\section{RESULTS}

In the present study, 20 in-depth interviews (IDI) were conducted. The mean age of study participants was 1.5 (SD: 0.51) years. Half of the study participants were male. The majority of the study participants (25\%) were involved in the business, $20 \%$ were students, and the rest of them (55\%) were involved in different types of occupations. Most of them (40\%) were living in rural areas, and $35 \%$ and $25 \%$ were living in urban and semi-urban areas, respectively (Table 1). On the contrary, case-specific information of study participants was also illustrated (Table 2).

\section{Theme-01 : Perceptions regarding telemedicine service}

When participants were asked to state perceptions regarding telemedicine, the majority of the study participants said that telemedicine is an online service through which they received health care services particularly primary health care services provided by the doctors through the assistance of phone or internet. A university student (female) explained her perception of telemedicine as:

"Telemedicine is an online primary treatment service provided by the doctors that services are adopted by us while not attending to the hospital as well as staying at home over the assistance of a phone." [Case: 03; Age: 24 years]
Other participants expressed their perceptions in the following way:

"By using the telephone as well as purchasing megabytes (MB) for using telemedicine apps for receiving the doctor's advice when we suffer from any kind of illness or disease is called telemedicine." [Case: 01; Age: 38 years] "When we make a bridge between doctors and patients over the phone for taking healthcare services is regarded as telemedicine." [Case: 02; Age: 22 years]

"Telemedicine is a system through which we are able to get healthcare services but not emergency services by using hotline number or apps through using Wi-Fi from several doctors from several disciplines by paying the doctor's treatment fees." [Case; 20; Age: 22 years]

Theme-02: Participant's perceptions regarding telemedicine's barriers during the COVID19 pandemic

The majority of participants shared their perceptions toward the barriers of telemedicine service in several sections, which were categorized into different subthemes:

\section{Sub-theme 2.1 : Lack of trustworthiness in telemedicine services}

Maximum study participants shared their experience that they couldn't put trust during the period of taking online telemedicine services because they were afraid of becoming a sufferer from another vulnerable health 


\begin{tabular}{|c|c|c|c|c|}
\hline Case no. & Age (years) & Gender & Occupation & Residence \\
\hline 01 & 38 & Male & Business & Rural \\
\hline 02 & 22 & Female & Student & Urban \\
\hline 03 & 24 & Female & Student & Rural \\
\hline 04 & 34 & Female & Govt. job & Semi-Urban \\
\hline 05 & 25 & Male & Private job & Rural \\
\hline 06 & 19 & Female & Student & Rural \\
\hline 07 & 29 & Female & House-wife & Urban \\
\hline 08 & 27 & Male & Doctor & Urban \\
\hline 09 & 25 & Male & Business & Rural \\
\hline 10 & 30 & Male & Business & Urban \\
\hline 11 & 28 & Male & Business & Rural \\
\hline 12 & 32 & Female & House-wife & Rural \\
\hline 13 & 30 & Female & Teacher & Semi-Urban \\
\hline 14 & 26 & Male & Private job & Urban \\
\hline 15 & 34 & Female & Private job & Urban \\
\hline 16 & 21 & Female & Student & Semi-Urban \\
\hline 17 & 37 & Male & Teacher & Semi-Urban \\
\hline 18 & 27 & Male & Business & Rural \\
\hline 19 & 29 & Female & Govt. job & Semi-Urban \\
\hline 20 & 22 & Male & Teacher & Urban \\
\hline
\end{tabular}

condition if the treatment creates negative effects on them via telemedicine. Some are exemplified below: "A university student told that she had been felt confused towards telemedicine doctors that actually were they doctors or not? For this reason, she couldn't put her entire trust to take telemedicine services." [Case: 02, Age: 22 years]

"A patient suffering from asthma depicted that he couldn't take telemedicine in this coronavirus situation because he was confused about the doctor's treatment. He also added that if the doctors from other disciplines provide him treatment, he will suffer from another disease because the doctors are not specialized in this field to give him asthma-related treatment." [Case: 18; Age: 27 years]

"A study respondent told that one of his relatives took telemedicine services for her allergy-related problems, but she faced other severe problems besides allergy problems due to taking medicine from telemedicine service providing doctor's, and finally she lost her trust in telemedicine services. As a consequence, he lost his trust in it because he didn't agree to create other problems in this COVID-19 pandemic due to lack of healthcare facilities in hospitals during this vulnerable moment." [Case: 14, Age: 26 years]

\section{Sub-theme 2.2: Lack of access to get emer- gency diagnostic services}

The majority of the participants portrayed their perception and real-life experiences that they were faced several problems during the time of taking diagnostic services by using telemedicine. Some statements of the participants are given below:

"A patient had been tormented by back pain because of prolapse in the disk in the backbone shared that he had been facing this drawback since 1.5 years past and through the COVID-19 pandemic, he was unable to take treatment over telemedicine as a result of due to lockdown he can't do X-Ray and can't give the current scenario of his problems to the doctors" [Case: 01; Age: 38 years]

Other study participants also added that: 
"We need check-ups for our illness when we consult a doctor. Without any testing procedure, it would be harmful to receive treatment. However, via telemedicine patients don't seem to be getting this scope that was faced by me after I took service for my severe anemic problem wherever I used to be unable to test hemoglobin level immediately" [Case: 07; Age: 29 years]

"A few days ago, one of my friends had a bike accident. From his residence Upazila health complex is far away. Then he called the telemedicine service center for primary treatment. But the telemedicine service provider can't give him a proper solution because duty doctors didn't sure is there any broken injury or not! Then he suggested my friend go to the hospital immediately! I think that's one of the major problems in telemedicine services. A few days ago, I also faced this same barrier during the time of taking telemedicine service when I faced severe pain in my ureter" [Case: 16; Age: 21 years]

\section{Sub-theme 2.3: Face to face communication gap for sharing health-related problems}

By using telemedicine, it was quite difficult for the patients for creating a suitable platform to share their health-related problems easily to the service providers because participants directly explained that a communication gap exists between physicians and patients such as linguistic barriers, face to face interaction gap, etc. while they receive services by telemedicine. Patient's statements are described below as an example: "An anemic patient expressed her opinion that she was not satisfied when she took telemedicine services for her treatment due to lack of face to face contact with the doctor and also told that through the telemedicine to build a close bridge of mind was quite difficult for her. As a result, the real existing problems couldn't be shared at that time of communication" [Case: 02, Age: 22 years]

"For the doctors, it's very difficult to collect the entire patient's contact numbers and can't count them who receive this service. Usually, doctors are getting feedback from patients and told them to come again after taking prescribed medicine for some days. But in a telemedicine service, doctors are very limited in numbers. For this reason, patients who earlier got the service from a doctor but later are unable to reach the same doctor due to doctors' different shifting hours, which create face to face communication gap. [Case: 06; Age: 19 years]

Another study respondent living in the rural area shared her experience in an alternative way as:
"For me, when I had taken telemedicine services during the COVID-19 pandemic with the help of my senior sister via mobile apps, I was totally at a fix at that time how I shared my kidney's problem with the doctors via telemedicine. I felt confused right at that moment because there was a lack of direct face communication, and I was unable to share my problems through an open mind approach" [Case: 12; Age: 32 years]

A medical student also reported that:

"I think usually, doctors need direct contact to give treatment to any patients. But over the phone, just listen to some symptoms; it's very tough to give any medication to a severe patient. Without examining the patients, it's very arduous to trace the disease which was faced by me a few weeks ago" [Case: 08; Age: 27 years]

Sub-theme 2.4: The networking problem is a major barrier to receiving the treatment services.

The majority of the participants explained that networking problems such as low frequency of network, load-shedding, and remote areas located at out of network coverage are facing problems for receiving treatment services via telemedicine. Diverse perceptions of networking barriers are illustrated below:

"A university going woman suffering from severe back pain expressed that her residing area was out of network coverage and due to frequent load-shedding she was unable to run her mobile besides telemedicine apps which frequently interrupt her to take telemedicine services in the lock down" [Case: 03; Age: 24 years]

"A patient shared her perception towards telemedicine barriers that she has been suffering from hypertension and unable to take telemedicine services due to having network problems in her living area which is more densely populated which may be creating an extra burden on the networking system" [Case: 13; Age: 30 years]

Another respondent added a statement in the perspective of her rural environment:

"Problematic network coverage is present in every SIM operator services so that rural people cannot get the service properly. Also, there are some remote areas in our country that are totally out of network coverage. In that case, besides me, people from those rural areas are also deprived of this service" [Case: 06; Age: 19 years]

\section{Sub-theme 2.5 : Financial problems to pay doctor's fees during taking telemedicine ser- vices.}

Two-thirds of the study participants shared their perceptions and experiences that they had to provide the 
doctor's fees, which crossed the limit of their earning capacity during unemployment situations due to COVID-19; as a consequence, they couldn't able to provide that fees and were unable to get healthcare services. Some of their statements towards the cost of telemedicine are given below:

"A study respondent disclosed that during this COVID19 pandemic he and his family were unable to earn money and during the crisis moment he was unable to pay the doctor's fee via telemedicine services when he was in severe disease condition which made him too much frustrated" [Case: 01; Age: 38 years]

"A heart disease patient shared that he was a school teacher, but due to lock down in this COVID-19 crisis moment he couldn't go to school and had no tuition which took him in a vulnerable situation for taking telemedicine services due to lack of money for paying telemedicine service cost" [Case: 17; Age: 37 years]

"It can sometimes see urban people can bear the cost of telemedicine service, but rural people usually pass their day hand-to-mouth, so this service is quite expensive for them. Even they are not used to this service; sometimes they even know how to call or how to buy an internet package if they needed an internet connection! At present, it is quite difficult for me to bear the cost as a liver cirrhosis patient in this COVID-19 pandemic" [Case: 09; Age: 25 years]

Theme-03: Urgent recommendations to overcome barriers of telemedicine services in the context of Bangladesh

The majority of the participants explained their recommendations to eliminate barriers by ensuring network coverage from root level to tertiary level with the help of government and non-governmental organizations (NGOs), reducing the cost of telemedicine services, ensuring the authenticity of the doctor's presence, which helps in putting trust on them as well as the SIM operators should consider their cost when we will take telemedicine services over phone or hot line. Some other recommendations of the study participants are exemplified below:

"We need to increase the number of doctors in telemedicine service and also need to include a feedback system from the patient so that the whole health care system will be developed gradually and help to decrease barriers of the telemedicine services. At the same time, we should create awareness in the rural and urban population regarding telemedicine services" [Case: 19; Age: 29 years old]

"Lack of advertisement sometimes causes some problems. Many people event don't know about telemedicine services. If the government takes the necessary steps and monitors this service under their supervision, I think many problems will be solved" [Case: 10; Age: 30 years old]

"If the government provides some extra facilities about telemedicine like- ensure the network coverage in every area and lessen the cost of telemedicine service by collaborating with international organizations then this service can create a new dimension throughout our country" [Case:6; Age:19 years old]

\section{DISCUSSION}

In the present study, we found insight perceptions and barriers regarding telemedicine services in Bangladesh during COVID-19 pandemic. The study revealed young adult's perceptions regarding telemedicine services. The majority stated that telemedicine is a system through which we are able to get healthcare services by using the internet, mobile application or just a phone call for receiving primary treatment from an expert doctor panel for any kind of less severe illness without going to the hospital. A previous study in Bangladesh showed that the majority of the participants (70\%) defined "Telemedicine Service" as electronic health-related services where patients receive medical treatment using technologies such as the internet, computer, or webcam ${ }^{2}$. Our study found that maximum participants shared their experience that they couldn't put trust in telemedicine service because they were afraid of becoming a sufferer from other vulnerable health conditions if the treatment creates negative or adverse effects on health. This finding is consistent with another study which showed that a lack of patient's trustworthiness was a significant barrier towards telemedicine services adaptation ${ }^{19}$. In our study, we found that the majority of participants explained their perceptions and real-life experiences that they were faced many problems during taking diagnostic services through the telemedicine service system which was unable to provide emergency diagnostic support during emergency situations in Bangladesh. Another study also found that telemedicine is not a viable option in providing diagnostic services; rather it just provides limited primary health care facilities to the patients ${ }^{22}$. In our study, it was seen to that the maximum participants mentioned the communication barriers they faced. As this service has occurred by technological facilities, people from different areas have their own language and absence one to one interactions; it's quite difficult to ensure the quality of treatment for virtual duty doctors. The patients also have not got much 
time to clarify their problems and also doctors sometimes face difficulties by the local accent of the patients. The previous studies also revealed that treatment via telemedicine does not provide face-to-face interaction and also linguistic barriers present regarding telemedicine services that make it difficult to build acceptable verbal communication between physicians and patients ${ }^{13,14}$. This study also pointed out that online communication has become a major obstacle. In Bangladesh people live in the countryside, where inadequate infrastructure including power supply, weak internet access, inadequate network connectivity interrupts patient-physician bridges in both urban and rural areas. The previous study also showed that shortfall access to affordable broadband at adequate connection speeds is another barrier for providing telemedicine services in rural areas ${ }^{12}$. Devastating pandemic COVID-19 has turned the entire nation stunned. It is also questionable to pay a high service charge for the unemployed to get telemedicine health care services. According to the findings of this study, two-thirds of the participants in the study reported their understanding and their perspective that they had to provide telemedicine service charges that exceeded the limit of the ability as they suffer unemployment issues due to COVID-19, so that they could not afford certain fees and also can't receive healthcare services which created barriers to them. Previous study in Bangladesh revealed that, according to one of the telemedicine users, "Telemedicine is expensive to get treatment services, and he gave a higher cost for a single consultation" ${ }^{23}$. We found such major barriers besides young adult's perceptions that should be coped with interactive healthcare systems in view of young adult's needs and requirements.

The study had a couple of limitations. Due to the pandemic-related public health restrictions, we could not able to collect data via face to face interviews, rather we performed telephonic interviews which created a communication gap between the interviewees and interviewers.

\section{CONCLUSION}

Findings from this study disclosed that Bangladeshi young adults had several perceptions towards telemedicine services based on their different sociodemographic and cultural views which almost try to cover telemedicine aspect. At the same time they also addressed the telemedicine barriers regarding lack of trustworthiness, emergency diagnostic barriers, absence of intimation between doctor and patient, network and financial barriers in COVID-19 pandemic. The governmental and private organizations have to come forward to work collaboratively and make telemedicine health care services available, reliable, and affordable for all across the country, and only true effort can make it happen.

\section{ETHICAL APPROVAL}

The study was carried out in accordance with the Institutional Research Ethics and the Declaration of Helsinki or its comparable ethical standards. In addition, the study's protocol was approved by Sheikh Sayera Khatun Medical College, Gopalganj, Bangladesh. In an informed consent form displayed prior to the questionnaire, participants were well briefed about the procedure, purpose of the study and told that their information would remain confidential. Data were collected anonymously, and all participants provided informed consent.

\section{ABBREVIATION}

ICT: Information and Communication Technology

DGHS: Directorate General of Health Services

WHO: World Health Organization

E-Health: Electronic Health

IDI: In-Depth Interviews

MB: Megabyte

SIM: Subscriber Identification Module

NGO: Non-Governmental Organization

\section{ACKNOWLEDGMENT}

The authors would like to thank all the participants who voluntarily participated in this study for providing their thoughtful responses.

\section{FUNDING}

None.

\section{CONFLICTS OF INTEREST}

The authors have no conflict of interest.

\section{REFERENCES}

1. Ryu S. Telemedicine: opportunities and developments in member states: report on the second global survey on eHealth 2009 (global observatory for eHealth series, volume 2). Healthcare informatics research. 2012;18(2):153-155. Available from: https://doi.org/10.4258/hir.2012.18.2.153.

2. Akhtar R, Alam S, Siddiquee NKA. Telemedicine: An ICT based healthcare approach to ensure health service for all. International Journal of Community Medicine and Public Health. 2019;6(9):3732. Available from: https://doi.org/10.18203/ 2394-6040.ijcmph20193961.

3. Ferdous AM. Scopes and challenges of implementing Telemedicine in a developing country like Bangladesh (Master's thesis, UiT Norges arktiske universitet). 2017;Available from: https://hdl.handle.net/10037/11275.

4. Grecu AM, Sharma G. The effect of telehealth insurance mandates on healthcare utilization and outcomes. Applied Economics. 2019;51(56):5972-5985. Available from: https://doi. org/10.1080/00036846.2019.1644448. 
5. Ohannessian R, Duong TA, Odone A. Global telemedicine implementation and integration within health systems to fight the COVID-19 pandemic: a call to action. JMIR public health and surveillance. 2020;6(2):e18810. PMID: 32238336. Available from: https://doi.org/10.2196/18810.

6. COVID-19: Whole of population telehealth for patients, general practice, primary care and other medical services. Retrieved 20 July 2020;Available from: https://www.health.gov.au/ministers/the-hon-greg-hunt-mp/ media/covid-19-whole- of-population-telehealth-for-patientsgeneral-practice-primary-care-and-other-medical-services.

7. Telehealth rules relaxed, but patients still face barriers. Retrived 20 July 2020;Available from: https: //www.mmm-online.com/home/channel/regulatory/ telehealth-rules-relaxed-but-patients-still-face-barriers/.

8. Opportunities and Barriers for Telemedicine in the U.S During the COVID-19 Emergency and Beyond). Retrived 20 July 2020;Available from: https://www.kff.org/womenshealth-policy/issue-brief/opportunities-and-barriers-fortelemedicine-in-the-u-s-during-the-covid-19-emergencyand-beyond/.

9. $82 \%$ of Young Adults Would Prefer Telehealth to InPerson Visit. Retrieved from 20 July 2020;Available from: https://www.beckershospitalreview.com/healthcareinformation-technology/82-of-young-adults-would-prefertelehealth-to-in-person-visit.html.

10. Ekeland AG, Bowes A, Flottorp S. Effectiveness of telemedicine: a systematic review of reviews. International journal of medical informatics. 2010;79(11):736-771. PMID: 20884286. Available from: https://doi.org/10.1016/j. ijmedinf.2010.08.006.

11. Telemedicine Reaches Beyond Clinic Walls. Retrieved 20 July 2020;Available from: https://www.ruralhealthinfo.org/ruralmonitor/telemedicine-reaches-beyond-clinic-walls/.

12. Telehealth Use in Rural Healthcare. Retrieved 20 July 2020;Available from: https://www.ruralhealthinfo.org/topics/ telehealth.

13. Hjelm NM. Benefits and drawbacks of telemedicine. Journal of telemedicine and telecare. 2005;11(2):60-70. PMID: 15829049. Available from: https://doi.org/10.1258/
1357633053499886.

14. Steele RE. Telemedicine in Greenland: the case for and against implementation. International journal of circumpolar health. 1998;57:686-688.

15. Ahmed T, et al. Digital Health and Inequalities in Access to Health Services in Bangladesh: Mixed Methods Study. JMIR mHealth and uHealth. 2020;8(7):e16473. PMID: 32706736. Available from: https://doi.org/10.2196/16473.

16. Coronavirus: Can telemedicine be the saviour in this pandemic? Retrieved 20 July 2020;Available from: https://www.dhakatribune.com/health/coronavirus/2020/ 04/13/coronavirus-can- telemedicine-be- the- saviour-in-thispandemic.

17. Hasan J. Effective telemedicine project in Bangladesh: Special focus on diabetes health care delivery in a tertiary care in Bangladesh. Telematics and Informatics. 2012;29(2):211-218. Available from: https://doi.org/10.1016/j.tele.2011.02.002.

18. Ahmed T, et al. eHealth and $m$ Health initiatives in Bangladesh: A scoping study. BMC health services research. 2014;14(1):19. PMID: 24934164. Available from: https://doi.org/10.1186/ 1472-6963-14-260.

19. Zobair KM, Sanzogni L, Sandhu K. Telemedicine Healthcare Service Adoption Barriers in Rural Bangladesh. Australasian Journal of Information Systems. 2020;p. 24. Available from: https://doi.org/10.3127/ajis.v24i0.2165.

20. Hasan J. Effective telemedicine project in Bangladesh: Special focus on diabetes health care delivery in a tertiary care in Bangladesh. Telematics and Informatics. 2012;29(2):211-218. Available from: https://doi.org/10.1016/j.tele.2011.02.002.

21. Rise of youth. Retrieved 20 July 2020;Available from: https:// www.thedailystar.net/rise- of-youth-51048.

22. Coronavirus: poor income drops $80 \%$ in Bangladesh. Retrieved 20 July 2002;Available from: https://www.aa.com. tr/en/asia-pacific/coronavirus-poor-income-drops- 80 -inbangladesh/1808837.

23. Hoque MR, Mazmum MFA, Bao Y. e-Health in Bangladesh: current status, challenges, and future direction. The International Technology Management Review. 2014;4(2):87-96. Available from: https://doi.org/10.2991/itmr.2014.4.2.3. 